\title{
Evaluation of the Swat River, Northern Pakistan, water quality using multivariate statistical techniques and water quality index (WQI) model
}

\author{
Shah Jehan $^{1} \cdot$ Ihsan Ullah ${ }^{2} \cdot$ Sardar Khan $^{2} \cdot$ Said Muhammad $^{1} \cdot$ Seema Anjum Khattak $^{1} \cdot \operatorname{Tariq~Khan~}^{3}$
}

Received: 29 October 2019 / Accepted: 10 June 2020 / Published online: 4 July 2020

(C) The Author(s) 2020

\begin{abstract}
This study evaluates the characteristics of water along the Swat River, Northern Pakistan. For this purpose, water samples $(n=$ 30) were collected and analyzed for physicochemical parameters including heavy metals (HM). The mean concentrations of physicochemical parameters and HM were within the drinking water guideline values set by the World Health Organization (WHO 2011) except $34 \%, 60 \%$, and $56 \%$ of copper $(\mathrm{Cu})$, nickel $(\mathrm{Ni})$, and lead $(\mathrm{Pb})$, respectively. Pollution sources were identified by various multivariate statistical techniques including correlation analysis (CA) and principal component analysis (PCA) indicating different origins both naturally and anthropogenically. Results of the water quality index (WQI) ranged from 13.58 to 209 with an average value of 77 suggesting poor water quality for drinking and domestic purposes. The poor water quality was mainly related to high sodium (alkalinity) and salinity hazards showing $>27 \%$ and $20 \%$ water samples have poor alkalinity and salinity hazards, respectively. Hazard quotient (HQ) and hazard index (HI) were used to determine the health risk of $\mathrm{HM}$ in the study area. For water-related health risk, $\mathrm{HQ}_{\text {ingestion, }} \mathrm{HQ}_{\text {dermal }}$, and $\mathrm{HI}$ values were $\geq 1$, indicating noncarcinogenic health risk (NCR) posed by these HM to the exposed population.
\end{abstract}

Keywords Waterquality index (WQI) model · Sodium adsorption ratio · Principal component analysis · Geostatistical techniques · Human health risk assessment $\cdot$ Swat River

\section{Introduction}

Water is the most limited and countable resource, and only a small fraction $(2.5 \%)$ of surface water is fresh and suitable for various purposes (household activities, agriculture practices, aquatic biochemical processes, and industrial maneuver) to humans and other living beings (Avci et al. 2018; Xiao et al. 2019). The investigation of water quality and its resources is essential for understanding the current state of water and the

Responsible Editor: Xianliang Yi

Shah Jehan

Jehanshah72@yahoo.com

1 National Centre of Excellence in Geology, University of Peshawar, Peshawar 25130, Pakistan

2 Department of Environmental Sciences, University of Peshawar, Peshawar 25120, Pakistan

3 Department of Environmental Sciences, University of Haripur, Haripur 26620, Pakistan main threats that have occurred over the past decades. Natural (i.e., erosion and weathering) and anthropogenic activities have drastically and exceedingly reduced the volume and quality of water globally (Jehan et al. 2019a; Rashid et al. 2019a). Anthropogenic factors are a set of different activities that depend on intensity and time. The quality of water can be damaged either from point or nonpoint sources, and point sources can easily be recognized by their direct discharge into water bodies (Hou et al. 2016; Mukate et al. 2019). Industrial zones and households are the main known point sources that discharge their effluents into surface waters like streams and rivers without treatment (Jehan et al. 2018). Point source is one of the serious problems in developing countries where most commonly people and concerned authorities do not follow the rules and regulations for the environment (Maillard and Santos 2008). Nonpoint sources pertain to a term where no point can exist but mostly surface runoff and agriculture practices are considered (Ekere et al. 2019).

The contamination of water sources has become an alarming issue in developing and developed countries over the last decades (Omonona et al. 2019) due to rapid 
urbanization and high-level agriculture practices especially in developing countries (Tripathi and Singal 2019). Water quality has a direct connection to humans and wastewater straightaway is used in agriculture sectors (Calazans et al. 2018; Ladwani et al. 2012). The use of municipal wastewater for agriculture is one of the established practices, particularly in urban and peri-urban regions. It is estimated that about $80 \%$ municipal wastewater in developing countries is used for crop irrigation (Zeng et al. 2015). Irrigation with wastewater and the use of fertilizers and pesticides greatly affect the physicochemical characteristics and quality of water (Ali et al. 2019; Rashid et al. 2019b).

Numerous studies have been conducted on the assessment of water quality using the water quality index (WQI) model to transform values of different water quality parameters into simple countable numbers so that each and every one can understand the status of water sources. Wu et al. (2018) assessed river water quality using the water quality index model in Lake Taihu Basin, China, suggesting moderate water quality in the basin. Mukate et al. (2019) developed a new integrated water quality index model (IWQI) to evaluate the suitability of groundwater in India. According to their adopted integrated model, drinking water was classified as $2 \%$ excellent, $8 \%$ poor, $8 \%$ unsuitable for drinking purposes, $39 \%$ good, and $43 \%$ as having marginal characteristics. Similarly, Solangi et al. (2019) evaluated groundwater quality using the WQI in Sujawal district, southern Sindh Province, Pakistan. Their finding revealed $2.13 \%, 6.38 \%, 13.83 \%, 22.34 \%$, and $55.32 \%$ of water samples, respectively, were excellent, good, unsuitable for drinking purposes, very poor, and poor.

In Pakistan, surface water quality is deteriorated through industrial discharge, agrofertilizers, and commercial and domestic sewages that released toxic pollutants to the surrounding environment. Usage of wastewater for irrigation is a popular and common practice in all agriculture countries because it supplies nutritional components and reduces expenditure over fertilizers (Lazarova and Bahri 2004). However, the long-term uses of municipal/industrial wastewater for irrigation not only affect the quality of soil but also cause phytotoxicity and human health and environmental problems. Likewise, a big problem associated with the use of such water is the augmenting of high salinity and excessive ammonium ions that leads to the phytotoxic nature of organic wastes which ultimately inhibit seed germination (El Hamouri et al. 1996). In the study area, the Batkhela canal is mainly used for irrigation purposes, and the population is exposed to the water by daily consumption for drinking and bathing. The inhabitants of the study area disposed their solid wastes and commercial and industrial effluents are released directly into the canal water. These anthropogenic activities may create a dangerous situation which needs an immediate attention. Indiscriminate discharge of domestic and industrial wastewater deteriorates the water quality of the study area. No comprehensive scientific studies exist to date about the surface water quality, sources of pollutants, and associated human health risk. Therefore, the present study focused on (1) the impacts of anthropogenic activities on surface water quality, (2) calculation of water quality by performing the water quality index model and sodium adsorption ratio, and (3) elaboration of human health risks for adults and children through ingestion and dermal contact.

\section{Study area}

\section{Location, climate, and rainfall patterns}

The study area (Fig. 1) lies within the geographic coordinates of $34-35^{\circ} \mathrm{N}$ and $71-72^{\circ} \mathrm{E}$ bounded by the Swat foothills in the north, the Mohmand Melange Complex and the district of Charsadda in the southwest, and the Kot Melange Complex in the west. The study area and its surrounding agricultural fields are recharged and irrigated by the Batkhela canal and its tributaries. Batkhela is a green and lush place surrounded by mountains from all sides and the Swat River is flowing to the west of the city from which a canal was drawn at Amandara for the purpose of irrigation and hydropower. The inhabitants of the study area are mainly associated with agricultural and farming sectors, growing major crops such as rice, maize, wheat, grains, barley, and vegetables. The area is popular for rice production where surface water supplemented with groundwater is used for irrigation. Therefore, the assessment of surface water and human health risk assessment are quite essential along the Swat River, Northern Pakistan.

Climatically subtropical and moist temperate zone dominated the study area with thunderstorm and snowfall (Barinova et al. 2013). The selected area has a hot summer $\left(41.9^{\circ} \mathrm{C}\right)$ and cold winter $\left(0.8^{\circ} \mathrm{C}\right)$. The hottest month is June with mean temperature of $33^{\circ} \mathrm{C}$ and and sometimes raised to $46{ }^{\circ} \mathrm{C}$, while the coldest month is January having average temperature of $1{ }^{\circ} \mathrm{C}$ to $-2{ }^{\circ} \mathrm{C}$. Winter is longer than summer, and the temperature usually falls below freezing point (November to March). According to the Pakistan Meteorological Department meteorological data, the average annual rainfall is $1003 \mathrm{~mm}$. Maximum rainfall occurs during the months of February $(162 \mathrm{~mm})$ and March $(231 \mathrm{~mm})$. The average relative humidity varies from a minimum of $40 \%$ in April to a maximum of $85 \%$ in July (Nafees et al. 2008). 
Fig. 1 Sampling location map of the study area

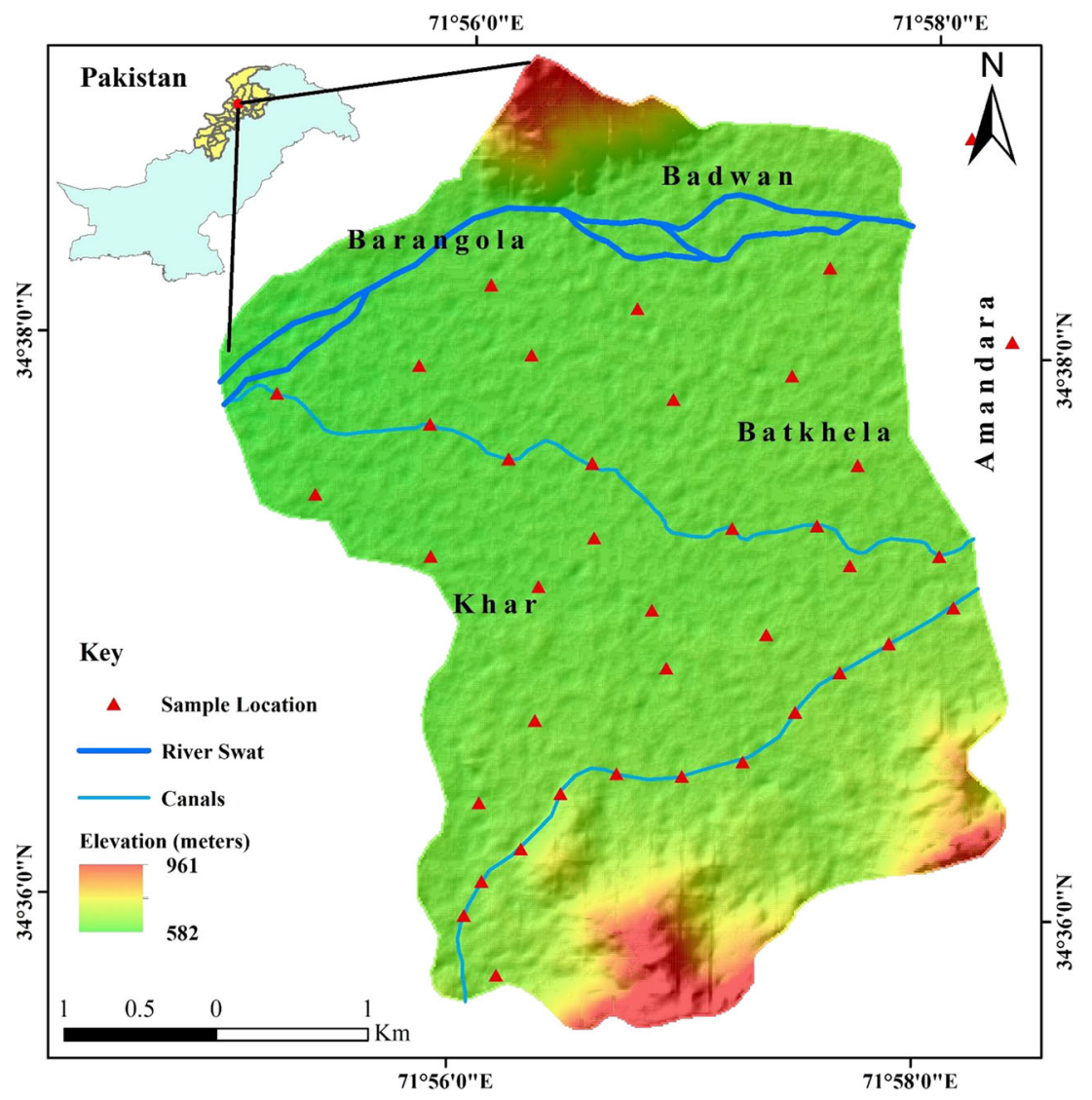

\section{Soil types, geomorphology, and drainage patterns}

Soil plays an important role in finding out the quantity as well as the quality of the water potential in the place. The study area soil is of five major types: Aridisols with limited leaching and water deficiency; Entisols on the unconsolidated parent rock material, on the steep slopes, and along the river course; Gelisols at extremely high elevation which is almost frozen throughout the year; Inceptisols which are found on a fairly steep slope and young geomorphic setting; and Mollisols, the world's most productive soil, which are at the middle to higher latitude of the study area.

Drainage pattern is an important factor that helps in the determination of potentiality of water (Nasir et al. 2018). The types of drainage and its density describe the surface/ subsurface characteristics like runoff, infiltration relief, and permeability. The runoff of an area is characterized by its drainage density as it is the quantum of relative rainwater that might have infiltrated. Hence, the lesser the runoff, the higher the probability of recharge. In the study area, the calculated drainage density is $1.002 \mathrm{~km}^{2}$ and the overall drainage pattern shows that drainage density is very high to high along the tributaries of the Swat River. Low to very low drainage was identified along the whole area of subvalleys from north to south in the form of local streams like small tributaries, ephemeral streams, and springs. The distribution of the drainage pattern across the valley is mainly attributed to the weak zones generated by past geological activities (Chuma et al. 2013).

\section{Hydrology and geological settings}

The occurrence and distribution of groundwater is regulated by different hydrological settings in the study area. Regional hydrology describes that how many of inhabitants of the area consumed different groundwater sources. All these water sources mostly receive recharge from precipitation. Shallow aquifers of groundwater have mostly low water table and are used for drinking, domestic, agriculture, and industrial purposes. The inhabitants consume water from groundwater sources like tube wells, hand pumps, dug wells, bore well, and springs. The municipal community tube well water is distributed through supply lines in the study area.

The regional geology of the study area includes different formations (Fig. 2), such as Alluvial Deposits (Qa), Kashala Formation (Rk), Malakand Granite (Tmg), Stream Deposit (Qs), Saidu Formation (RJs), Chakdara Granite Gneisses (Pcg), Indus suture mélange, Dir meta sediments, Peshmal Schist, Kohistan batholith, and granite formation. These formations consist of enriched minerals and rocks, i.e., RJs include a combination of graphitic phyllite with garnet grains with thinly laminated marble beds. Rk includes garnet bearing 
Fig. 2 Geological map showing the local setting and different formations of the study area (after Searle and Khan 1996)

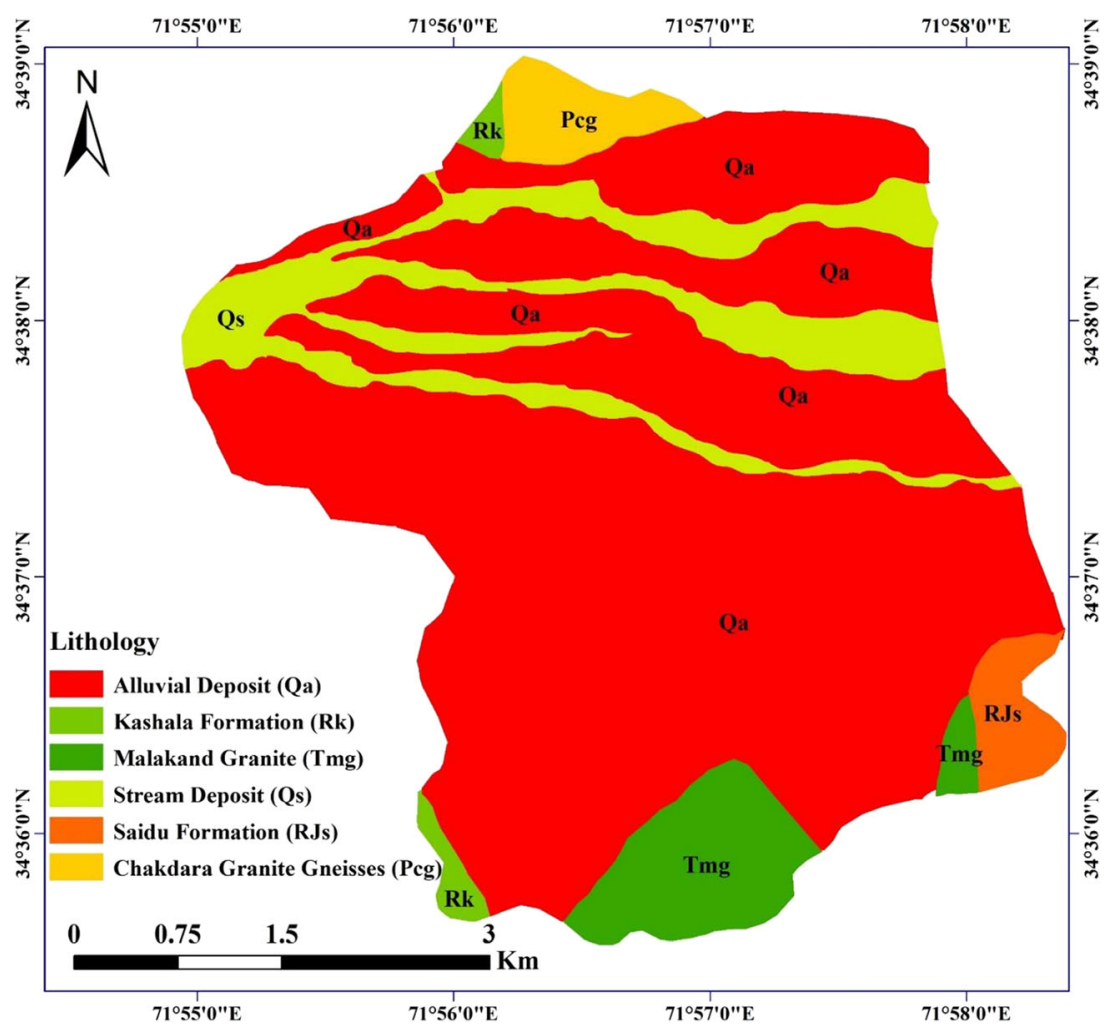

calcareous and graphitic schist, with thin bedded limestone and marble. Tmg is composed of amphibolites, schist, garnet, biotite, schist, and schistose marble, while Pcg contained granite with siliceous schist layer (Nasir et al. 2018; Searle and Khan 1996).

\section{Material and methods}

\section{Sampling collection and analysis}

Thirty water samples $(n=30)$ were collected in replicates from different sites in such a way that each sample shows equal representation of the study area. Samples were collected in $250 \mathrm{~mL}$ precleaned polythene bottles which were previously soaked and washed with $10 \% \mathrm{HNO}_{3}$ after an equal interval distance of $100 \mathrm{~m}$. During sampling collection, $\mathrm{pH}$, electrical conductivity (EC), and total dissolved solids (TDS) were determined in situ by a HANNA HI129 pH meter, conductivity meter (APHA 145), and TDS meter (APHA 208D), respectively. Before further analysis, water samples were kept at $4{ }^{\circ} \mathrm{C}$ and immediately transported to the laboratory of the National Centre of Excellence in Geology, University of Peshawar adopting the procedure of Rehman et al. (2018). Latitude and longitude coordinates were also noted for each sampling point using the global positioning system (GPS). Major anions viz. chloride $(\mathrm{Cl})$, sulfate $\left(\mathrm{SO}_{4}\right)$, and bicarbonate alkalinity $\left(\mathrm{HCO}_{3}\right)$ were determined by the trimetric titration respectively. The concentrations of light metals (LM) and HM were analyzed by flame atomic absorption spectrophotometer (FAAS-PEA 700, USA) and graphite furnace atomic absorption spectrometer (GFAAS-PEA 700, USA), respectively. Quality control and assurance were assessed using duplicates, reagent blanks, and certified reference materials (CRM 700), with each batch of water samples. Matrix interference (blank) was $<2 \%$ for all elements. Triplicates of sample analysis yielded relative percent differences of $<5 \%$. Each calibration curve was evaluated by analyses of quality control standards before, during, and after the analyses of a set of samples. When the recovery rate becomes out of the recommended range (90-110\%), samples were reanalyzed with a new calibration curve.

\section{Irrigation water quality assessment}

Irrigation water quality assessment (IWQA) denotes various mineral composition of water and was primarily developed for the assessment of water quality for irrigation purposes (Abbasnia et al. 2018). The chemical composition of irrigation water quality (IWQ) affects directly or indirectly crop yields and nutrient availability, respectively (Khalid 2019). IWQ was assessed by sodium adsorption ratio (SAR), sodium percentage $(\mathrm{Na} \%)$, residual sodium carbonate ( $\mathrm{RSC})$, magnesium adsorption (MAR), and Kelly ratio (KR) in this study. method and using UV-visible DR (500) spectrophotometer, 
SAR for irrigation water quality was evaluated using the following equation adopted by Xiao et al. (2019).

$\mathrm{SAR}=\mathrm{Na} /[(\mathrm{Ca}+\mathrm{Mg})]^{0.5}$

Four categories were identified for salinity hazard starting from very high to very low as follows: $\mathrm{C} 4$ (very high, $\mathrm{EC}>$ $2250 \mu \mathrm{S} / \mathrm{cm}$ ), C3 (high, $750<\mathrm{EC}<2250 \mu \mathrm{S} / \mathrm{cm}$ ), C2 (medium, $250<\mathrm{EC}<750 \mu \mathrm{S} / \mathrm{cm}$ ), and $\mathrm{C} 1$ (low, $\mathrm{EC}<250 \mu \mathrm{S} / \mathrm{cm}$ ). Likewise, the alkalinity (sodium) hazard was also distributed into four classes starting from very high to low alkalinity hazards: S4 (very high, SAR > 26), S3 (high, $18<\mathrm{SAR}<$ 26), S2 (medium, $10<\mathrm{SAR}<18$ ), and S1 (low, SAR < 10) (Raju et al. 2011). Na\%, RSC, MAR, and KR are crucial components for IWQA and were determined using the following equations as adopted by Selvakumar et al. (2017).

$$
\begin{aligned}
& \mathrm{Na} \%=(\mathrm{Na}+\mathrm{K}) /(\mathrm{Ca}+\mathrm{Mg}+\mathrm{Na}+\mathrm{K})^{100} \\
& \mathrm{RSC}=\left[\left(\mathrm{HCO}_{3}+\mathrm{CO}_{3}\right)-(\mathrm{Ca}+\mathrm{Mg})\right] \\
& \mathrm{MAR}=\mathrm{Mg} \times 100 / \mathrm{Ca}+\mathrm{Mg} \\
& \mathrm{KR}=\mathrm{Na} / \mathrm{Ca}+\mathrm{Mg}
\end{aligned}
$$

$\mathrm{Na} \%$ and $\mathrm{RSC}$ are categorized into 3 major types for IWQA, i.e., suitable $(\mathrm{Na} \%<30$, RSC $<1.25)$, marginalized suitable (Na\% 30-60, RSC 1.25-2.5), and unsuitable $(\mathrm{Na} \%>60, \mathrm{RSC}>2.5)$ (Li et al. 2016). The maximum acceptable level for MAR is $50 \mathrm{meq} / \mathrm{L}$, above which water is considered unsuitable for IWQ (Mahfooz et al. 2019). KR values greater than 3.00 and less than 1.00 are considered unsuitable and suitable for irrigation purposes, respectively (Kelly 1957).

\section{Water quality index model}

The WQI model is an important tool for testing water quality in terms of its potability and management perspective. The WQI model is a water rating scale that reflects the combined influence of a variety of parameters on the overall quality of water (Mohebbi et al. 2013). According to Ekere et al. (2019), WQI was first formulated by Horton (1965) as the numerical procedure to identify water quality from the Ohio River Valley Water Sanitation Commission United States of America. It is very effective in the provision of water quality data in a very simple way to the public, policymakers, and management authorities for making law and legislation for safety water uses. These indices are used for the significant assessment of water quality in various countries of the world (Khalid 2019). The WQI model was computed using the following equation (Eq. 6):

$\mathrm{WQI}=\sum[W i \times(C i / S i) \times 100]$

Where $W_{i}=w_{i} / w_{i}$ is the relative weight, and $w_{i}$ is the assigned weight ranging from 1 to 5 which is the attribution of each element according to its relative effect on drinking water and human health; 1 and 5 values are assigned to parameters with least to highest critical health effects, respectively. For example, $\mathrm{Pb}$ and $\mathrm{Cr}$ assigned the highest weight of 5 (Table 1) were considered toxic for health. $w_{i}$ is the weight of the $i$ th parameter and is the sum of $w_{i}, S_{i}$ is the drinking water guideline value (WHO), and $C_{i}$ is the measured trace element concentration of each element (Khalid 2019). Based on the WQI model, water quality can be divided into 5 categories as follows: (1) (WQI < 50, excellent water quality); (2) $(100 \leq \mathrm{WQI}$ $<200$, poor water quality); (3) $(200 \leq \mathrm{WQI}<300$, very poor); and when (WQI $\geq 300$ ), water was unsuitable for drinking purposes (Mukate et al. 2019).

\section{Risk assessment}

To assess human health risk of HM in the water compartment of the study area, ingestion through drinking and skin absorption through dermal contact are usually considered (Zeng et al. 2015). The dietary average daily dose (ADD) exposures for direct ingestion $\left(\mathrm{ADD}_{\text {ingestion }}\right)$ and dermal absorption $\left(\mathrm{ADD}_{\text {dermal }}\right)$ were obtained using Eqs. (7) and (8) (USEPA 2011) shown as follows:

$\mathrm{ADD}_{\text {ingestion }}=\frac{\mathrm{CW} \times \mathrm{IR} \times \mathrm{EF} \times \mathrm{ED}}{\mathrm{BW} \times \mathrm{AT}}$

$\mathrm{ADD}_{\text {dermal }}=\frac{\mathrm{CW} \times \mathrm{SA} \times \mathrm{Kp} \times \mathrm{EF} \times \mathrm{ET} \times \mathrm{ED}}{\mathrm{BW} \times \mathrm{AT}}$

Where $\mathrm{Cw}$ is the average value $(\mu \mathrm{g} / \mathrm{L})$ of HM in the water sample; IR is the daily intake (ingestion) rate (L/day), which was 2.0 and 0.64 for adults and children, respectively (Xiao et al. 2019); SA is the surface skin area $\left(\mathrm{cm}^{2}\right), 1800 \mathrm{~cm}^{2}$ for adults and $6660 \mathrm{~cm}^{2}$ for children; EF is the exposed frequency (days/year), which was taken 350 days/year in this study (Xiao et al. 2019; Zeng et al. 2015); ET is the exposure time (h/day), $0.58 \mathrm{~h} /$ day for adults and $1.0 \mathrm{~h} /$ day for children (Wang et al. 2011); ED is the exposure duration in years, 70 years for adults and 6 years for children (USEPA 2011); BW is the average body weight $(\mathrm{kg})$, $65 \mathrm{~kg}$ and $20 \mathrm{~kg}$ for adults and children, respectively (Xiao et al. 2019); and AT is the average time for noncarcinogenic (days); 25,550 days for adults and 2190 days for children (USEPA 2011). Kp is the skin adherence time in the samples $(\mathrm{cm} / \mathrm{h})$, $0.0001 \mathrm{~cm} / \mathrm{h}$ for $\mathrm{Pb}, 0.001 \mathrm{~cm} / \mathrm{h}$ for $\mathrm{Cu}, 0.004 \mathrm{~cm} / \mathrm{h}$ for $\mathrm{Ni}$ and $\mathrm{Co}$, and $0.0006 \mathrm{~cm} / \mathrm{h}$ for $\mathrm{Zn}$ as taken in this study (USEPA 2011). The noncarcinogenic risk (NCR) was calculated by the hazard quotient value (HQ) as shown in Eq. (9); (USEPA 2011). When HQ value $\geq 1$, then this predicts potential noncarcinogenic effects.

Hazard Quotient $(\mathrm{HQ})=\mathrm{ADD} / \mathrm{RfD}$ 
Table 1 Statistics of physicochemical parameters and the parameters for Water Quality Index calculation

\begin{tabular}{|c|c|c|c|c|c|c|c|c|c|}
\hline \multirow[t]{2}{*}{ Parameter } & \multirow[t]{2}{*}{ Unit } & \multirow[t]{2}{*}{ WHO } & \multicolumn{5}{|c|}{ Descriptive statistics } & \multicolumn{2}{|c|}{ Parameters for WQI calculation } \\
\hline & & & Min & Max & Ave & SD & SE & Weight (wi) & Relative weight (Wi) \\
\hline $\mathrm{pH}$ & & $6.5-8.5$ & 7.00 & 8.21 & 7.23 & 0.38 & 0.06 & 4.00 & 0.05 \\
\hline $\mathrm{EC}$ & $\mu \mathrm{S} / \mathrm{cm}$ & 1500 & 103 & 1260 & 426 & 289.25 & 52.8 & 4.00 & 0.05 \\
\hline TDS & $\mathrm{mg} / \mathrm{L}$ & 1000 & 65.9 & 806.0 & 228 & 189.03 & 34.5 & 4.00 & 0.05 \\
\hline $\mathrm{Cl}$ & $\mathrm{mg} / \mathrm{L}$ & 200 & 35 & 115 & 93.01 & 14.11 & 1.25 & 4.00 & 0.10 \\
\hline $\mathrm{SO}_{4}$ & $\mathrm{mg} / \mathrm{L}$ & 500 & 76.0 & 168 & 113 & 19.0 & 7.83 & 3.00 & 0.07 \\
\hline $\mathrm{HCO}_{3}$ & $\mathrm{mg} / \mathrm{L}$ & 500 & 116 & 430 & 101 & 23.0 & 3.91 & 1.00 & 0.02 \\
\hline $\mathrm{Na}$ & $\mathrm{mg} / \mathrm{L}$ & 200 & 17.2 & 39.63 & 24.3 & 6.30 & 1.15 & 3.00 & 0.04 \\
\hline $\mathrm{K}$ & $\mathrm{mg} / \mathrm{L}$ & 12 & 2.10 & 16.31 & 7.03 & 3.87 & 0.70 & 2.00 & 0.02 \\
\hline $\mathrm{Ca}$ & $\mathrm{mg} / \mathrm{L}$ & 75 & 27.2 & 125.2 & 101 & 19.44 & 3.54 & 2.00 & 0.02 \\
\hline $\mathrm{Mg}$ & $\mathrm{mg} / \mathrm{L}$ & 50 & 21.2 & 41.10 & 26.7 & 4.77 & 0.87 & 2.00 & 0.02 \\
\hline $\mathrm{Zn}$ & $\mu \mathrm{g} / \mathrm{L}$ & 3000 & 9.00 & 74.00 & 26.3 & 14.45 & 2.63 & 3.00 & 0.04 \\
\hline Co & $\mu \mathrm{g} / \mathrm{L}$ & 50 & 8.00 & 48.00 & 22.6 & 10.48 & 1.21 & 1.00 & 0.01 \\
\hline $\mathrm{Cu}$ & $\mu \mathrm{g} / \mathrm{L}$ & 50 & 12.0 & 57.00 & 32.6 & 12.72 & 2.23 & 2.00 & 0.03 \\
\hline $\mathrm{Ni}$ & $\mu \mathrm{g} / \mathrm{L}$ & 20 & 1.00 & 71.00 & 27.8 & 21.01 & 3.83 & 4.00 & 0.05 \\
\hline $\mathrm{Pb}$ & $\mu \mathrm{g} / \mathrm{L}$ & 10 & 2.00 & 18.00 & 9.3 & 3.43 & 0.62 & 5 & 0.06 \\
\hline
\end{tabular}

Where RfD is the reference dose $(\mu \mathrm{g} / \mathrm{kg} /$ day $)$ for the different analytes; $\mathrm{RfD}_{\text {dermal }}=\mathrm{RfD} \times \mathrm{ABS}_{\mathrm{g}}, \mathrm{RfD}_{\text {dermal }}$, and $\mathrm{RfD}$ ingestion are given in Table 3. $\mathrm{ABS}_{\mathrm{g}}$ is the gastrointestinal absorption factor, which is unitless. In this study, the RfD values are $3.8 \%$ for $\mathrm{Cr}$, $57 \%$ for $\mathrm{Cu}, 4.0 \%$ for $\mathrm{Ni}, 11.7 \%$ for $\mathrm{Pb}$, and $20 \%$ for $\mathrm{Zn}$ (Wang et al. 2017).

Furthermore, the total potential human NCR caused by different pathways was assessed by HI (Eq. 10):

Hazard Index $(\mathrm{HI})=\sum\left(\mathrm{HQ}_{\text {ing }}+\mathrm{HQ}_{\text {derm }}\right)$

Similarly, if the HI were found $\geq 1$, the toxic human health effect should be taken into consideration (USEPA 2011).

\section{Statistical analysis}

Multivariate statistical analysis of the HM concentrations was performed by Pearson's correlation analysis (CA) and principal component analysis (PCA) using Statistical Package for Social Sciences (SPSS Inc., version 20, Chicago, IL, USA). The Kaiser-Meyer-Olkin (KMO) and Bartlett's tests were conducted to test the suitability of the data for PCA (Varol 2011). KMO is a measure of sampling accuracy indicating which may be caused by underlying factors. A high value (relatively close to 1) generally indicates that PCA could be useful, as the case in this study, where $\mathrm{KMO}=0.36$. Bartlett's test of sphericity shows whether a correlation matrix is an identity matrix, which could indicate the variables are unrelated. The significance level of 0 in this study (less than 0.05) showed that there were significant relationships among the variables. Study area and contour maps of heavy metal distribution were drawn by ArcGIS software (10.2.2).

\section{Results and discussion}

\section{Water characteristics}

Descriptive statistics such as mean, minimum, maximum, standard deviation, and standard error of water quality parameters were performed and compared with the WHO (2011) drinking water guidelines (Table 1; Fig. 3). Water shows a slightly alkaline nature with average $\mathrm{pH}$ value of 7.34. The $\mathrm{pH}$ value in $30 \%$ of the samples exceeded the WHO (2011) drinking water guideline value, which can affect the mucous membrane (Xiao et al. 2019). Both EC and TDS values were found lower than the WHO (2011) guideline (Fig. 3a). Chloride is a significant major anion that is released from both geogenic and anthropogenic sources like weathering, erosion, atmospheric deposition, agrofertilizers, and effluents/leachates from industries. The mean $\mathrm{Cl}$ concentration $(93.01 \mathrm{mg} / \mathrm{L})$ was found lower than the recommended $(200 \mathrm{mg} / \mathrm{L})$ WHO health guideline. A high concentration of $\mathrm{Cl}$ in drinking water does not pose toxicity to humans, but it imparts a detectable salty taste in water above $200 \mathrm{mg} / \mathrm{L}$ concentration (Samantara et al. 2017). The mean values of $\mathrm{SO}_{4}$ and bicarbonate $\mathrm{HCO}_{3}$ were 113 and $101 \mathrm{mg} / \mathrm{L}$, respectively, which were below the WHO health guideline (500) value as shown in Table 1. Both anions do not pose any significant health risk; 

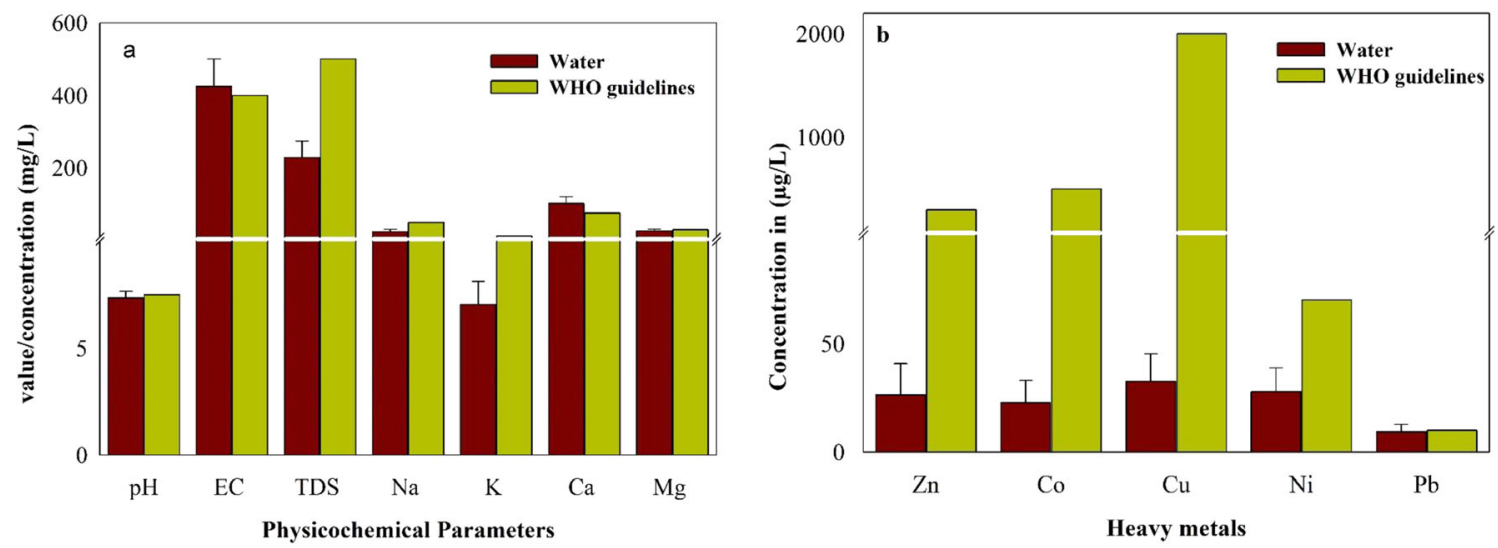

Fig. 3 Comparison of a physicochemical parameters and $\mathbf{b}$ heavy metals in water samples of the study area with international standards

however; their high concentration than normal deteriorates water quality causing problem which may risk our health. The dominance of anions was in the order of $\mathrm{Cl}>\mathrm{HCO}_{3}>$ $\mathrm{SO}_{4}$. The average concentrations of all LM (except $\mathrm{Ca}$ which exceeded in $90 \%$ of the water samples) were within the permissible limits of drinking water guideline values set by the WHO (2011) (Fig. 3a). Both $\mathrm{Ca}$ and $\mathrm{Mg}$ are important micronutrients which are essential for the human body and mainly originate from dissolution of $\mathrm{CO}_{3}$ minerals and dolomitic rocks, respectively. $\mathrm{Na}$ and $\mathrm{K}$ generally originate from dissolution of clay minerals and evaporates and silicates (Avci et al. 2018). The order of abundance of $\mathrm{LM}$ is $\mathrm{Ca}>\mathrm{Mg}>\mathrm{Na}>\mathrm{K}$, which is in accordance with the study conducted by Sánchez et al. (2017) in water-rock interactions in the urban area of Puebla Valley aquifer (Mexico). The mean concentration of all $\mathrm{HM}$ was found lower except in $34 \%, 60 \%$, and $56 \%$ of $\mathrm{Cu}, \mathrm{Ni}$, and $\mathrm{Pb}$, respectively (Fig. 3b). Among $\mathrm{HM}, \mathrm{Pb}$ is one of the most toxic and carcinogenic metals that enter into water bodies from various anthropogenic sources via household, paint, vehicles, and industrial emission (Arain et al. 2009). Pb has potential geogenic mafic and ultramafic sources already assessed by many researchers in the study area (Khan et al. 2018; Liu et al. 2020; Rashid et al. 2018). Its toxicity can be seen in a little amount in humans causing disorders in the human nervous system and affecting the digestive as well as the skeletal system. The mean concentration of $\mathrm{Pb}$ was found higher than that in the studies by Ashraf et al. (1991) in water from three freshwater reservoirs on the Indus River, Pakistan, and Ilyas and Sarwar (2003) in drinking water samples in the vicinity of Palosai drains, Peshawar. Similarly, Ni is a significant toxic HM causing various diseases such as allergy, dermatitis problems, and kidney disorders, and chronic exposure is associated with cancer risk. The mean concentration of $\mathrm{Ni}$ was found higher than those reported by Haq (2005) in surface and groundwater contamination in NWFP (former name of Khyber Pakhtunkhwa) and Sindh provinces, Pakistan.
Anthropogenic activities like agriculture and the industries in the surrounding vicinity of streams, rivers, and canals can contaminate water severely and such contamination becomes serious in densely populated areas especially in unplanned urban cities (Rehman et al. 2008). The concentration of HM was greater compared with light metals in all the studied water samples (Fig. 3a, b) in the present study.

\section{Hydrochemical facies of the study area}

The Gibbs (1970) diagram is useful for the valuation and estimation of different mechanisms that control the hydrogeochemistry of an area mainly influenced by three components: precipitation, weathering of parent rocks, and evaporation. The water composition is controlled by ambient climatic conditions, groundwater movement, and mineral features. Therefore, for evaluation of hydrochemical features and groundwater interactions, the Gibbs diagram was designed to establish a connection between the aquifer's geology and water composition (Gibbs 1970). For understanding the mechanism for hydrogeochemical control, water data was arranged by plotting total dissolved concentrations (TD) versus anion combination of $\left(\mathrm{Cl}^{-} /\right.$ $\left.\mathrm{Cl}^{-}+\mathrm{HCO}_{3}^{-}\right)$and weight ratio of cation concentrations $\left(\mathrm{Na}^{+} / \mathrm{Na}^{+}+\mathrm{Ca}^{++}\right)($Gibbs 1970; Fig. 4 a and b). The water type of the study area along the Swat River, Northern Pakistan, mostly falls into a rock-dominant region admitting that surrounding rocks previously discussed in study geology have a great influence on the water data. Thus, the Gibbs diagram (Fig. 4 a and b) deciphered that weathering of parent rocks and regional hydrogeological settings play a key role in water composition and chemistry. Further, some of the water features next to rock dominancy fall into recharge and cation exchange mechanism that make a suitable proportion for water composition in the study area.

Chadha (1999) proposed the hydrochemical characteristic for the classification of water data by plotting data focused on the differences of cations and anions in terms of presenting \% 


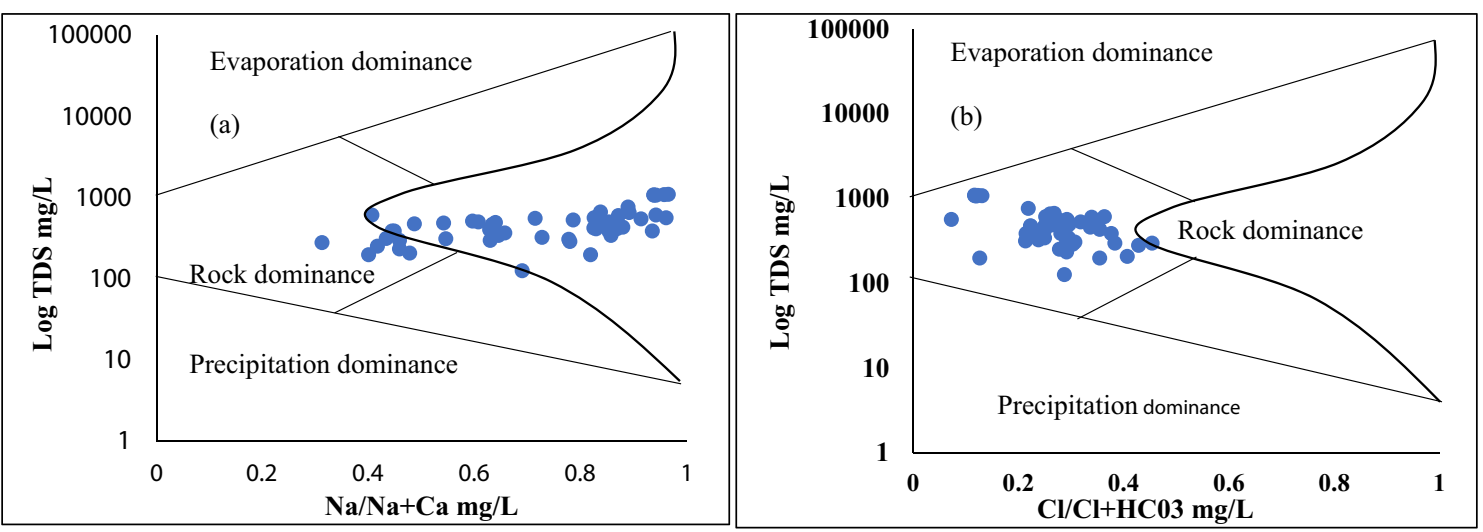

Fig. 4 a, b Schematic diagram to understand the major ion chemistry and mechanism controlling water chemistry along the Swat River, Pakistan. Data were plotted as $\mathrm{Na} / \mathrm{Na}+\mathrm{Ca} \mathrm{mg} / \mathrm{L}$ versus $\mathrm{Log} \mathrm{TDS}$ and $\mathrm{Cl} / \mathrm{Cl}+\mathrm{HCO}_{3} \mathrm{mg} / \mathrm{L}$ versus $\mathrm{Log}$ TDS

$\left[\mathrm{HCO}_{3}\right.$ and $\left.\left(\mathrm{Cl}+\mathrm{SO}_{4}\right)\right]$ concentrations in meq/L as percentage versus $(\mathrm{Ca}+\mathrm{Mg})$ and $(\mathrm{Na}+\mathrm{K})$ concentrations in meq/L (Chadha 1999). The resulting figure (Fig. 5) has four fields which described different types of hydrogeochemical processes responsible for water type formations. More than half $(n=17)$ of the samples had $\mathrm{NaHCO}_{3}$ water type, $n=9$ water samples were $\mathrm{CaHCO}_{3}$ water type, whereas $n=3$ water samples comprised the $\mathrm{Ca}-\mathrm{Mg}-\mathrm{Cl}$ water type, and the remaining water samples $(n=1)$ fell in the category of $\mathrm{NaCl}$ type (Fig. 5).

\section{Water quality assessment}

The water quality assessment was composed of three components: (1) comparison of HM concentrations with water quality standard (WHO), (2) assessment of water quality for irrigation purposes, and (3) evaluation of water quality using WQI. The HM concentrations were above the drinking water guideline value set by the WHO (2011) in 33\%, 55\%, and $65 \%$ of the samples for $\mathrm{Cu}, \mathrm{Ni}$, and $\mathrm{Pb}$, respectively, indicating contamination and undrinkable status of water quality. The main pollution elements were $\mathrm{Cu}, \mathrm{Ni}$, and $\mathrm{Pb}$ in the study area.

SAR value ranged from 10.72 to 20.67 with a mean value of 13.51 (Table 2). According to sodium hazard, SAR values $>9$ were regarded as unsuitable for irrigation purpose (Khalid 2019). In view of the current result, $73 \%$ of the samples were found in good quality, while $27 \%$ of the water samples were of acceptable quality as shown in Table 2. High SAR values create sodium salinity hazards by reducing the ratio of calcium and magnesium which
Fig. 5 The Chadha diagram identifies different water type formations along the Swat River, northern Pakistan. After Chadha (1999). Field 1: $\mathrm{Ca}-\mathrm{HCO}_{3}$ type water indices, representing both recharge and weathering processes. Field 2: $\mathrm{Ca}-\mathrm{Mg}-\mathrm{Cl}$ type waters, reflecting reverse ionexchange processes. Field 3: $\mathrm{Na}$ $\mathrm{Cl}$ type waters, indicating evaporation is the principal mechanism. Field 4: $\mathrm{Na}-\mathrm{HCO}_{3}$ type waters, reflecting cationic and ionic exchange processes

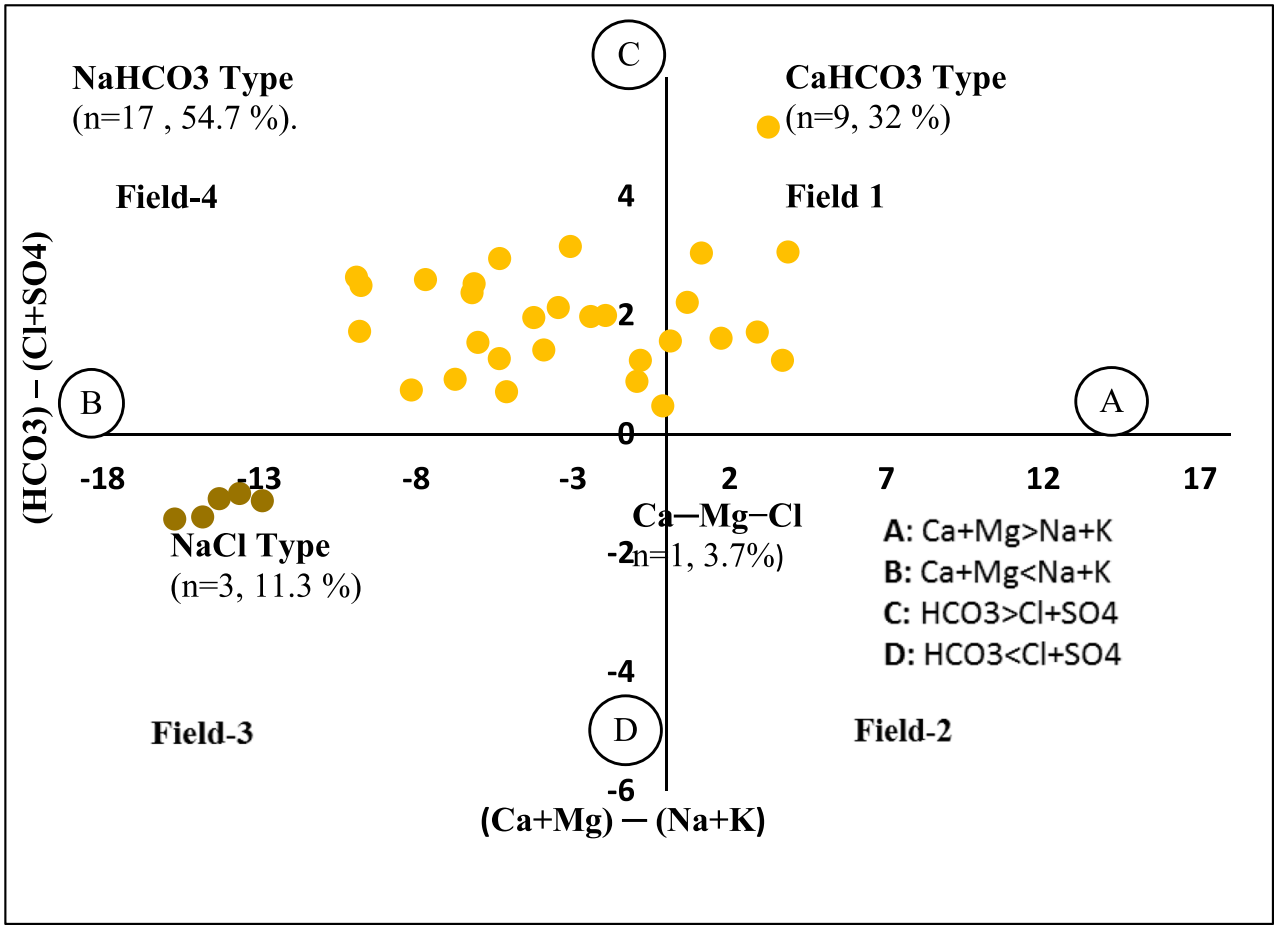


Table 2 Classification of water quality for irrigation purposes in the study area

\begin{tabular}{|c|c|c|c|c|}
\hline \multirow[t]{2}{*}{ Water class } & \multicolumn{2}{|c|}{ Salinity hazards } & \multicolumn{2}{|c|}{ Alkali hazards } \\
\hline & $\mathrm{EC}(\mu \mathrm{S} / \mathrm{cm})$ & Number of samples $(\%)$ & SAR (epm) & Number of samples (\%) \\
\hline Excellent & Up to 250 & 24 & Up to 10 & - \\
\hline Good & $250-750$ & 56 & 10 to 18 & 73 \\
\hline Fair/medium & $750-2250$ & 20 & 18 to 26 & 27 \\
\hline Poor/bad & $2250-5000$ & & $>26$ & - \\
\hline
\end{tabular}

cause infertility and retardation in plants and crops. In addition, $\mathrm{Na} \%$ and RSC showed IWQ suitable to marginal suitable except in $23 \%$ and $29 \%$ of the samples, respectively. Higher RSC value in the study area shows excess dissolution of carbonates in addition to alkaline earth elements (AEE) that render the water unsuitable for irrigation purposes in terms of RSC. MAR values in all the sampling points were recorded above $50 \mathrm{meq} / \mathrm{L}$ which is in good agreement with the study conducted by Mahfooz et al. (2019). KR value ranges from 21.4 to $41.3 \mathrm{meq} / \mathrm{L}$ in all sampling sites suggesting water unsuitable for irrigation purposes.

WQI was applied to get a more comprehensive understanding of the water quality in the subdistrict of Batkhela along the Swat River, Pakistan (Table 1). Results of the current study illustrated that WQI ranged from 13.58 to 209 with an average value of 77 . According to the water quality index, the water quality of the study area was poor for drinking and domestic purposes. This could be attributed to the presence of a high concentration of HM and variation in some of the other physicochemical parameters due to anthropogenic and geological sources. Anthropogenic activities like agriculture and the industries in the surrounding vicinity of streams, rivers, and canals can contaminate water severely and such contamination becomes serious in densely populated areas especially in unplanned urban cities (Rehman et al. 2008). The results of our study are in good agreement with the study conducted by Khalid (2019) in three districts of Baluchistan Province, Pakistan, and by Xiao et al. (2019) on water quality and health risk assessment of trace metals in river and well water in the
Chinese Loess Plateau. They concluded that the major proportion of their study possessed very poor water quality.

\section{Human health risk assessment}

Table 3 shows HQ and HI values for water quality of Batkhela subdistrict along the Swat River, Pakistan. According to the health risk assessment model recommended by the USEPA, the NCR to personal health of the HM in water were calculated. Two population groups comprised of adults and children were considered. For water-related health risk, $\mathrm{HQ}_{\text {ingestion, }}$ $\mathrm{HQ}_{\text {dermal }}$, and $\mathrm{HI}\left(\mathrm{HQ}_{\text {ingestion }}+\mathrm{HQ}_{\text {dermal }}\right)$ were classified as low to high indicating moderate to significant potential haz-

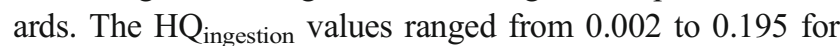
adults and 0.002 to 0.203 for children. These values indicated that the ingestion exposure had no adverse health effect on the human body and posed no potential noncarcinogenic risk. The $\mathrm{HQ}_{\text {dermal }}$ values of the toxic $\mathrm{HM}$ in adults and children were $\geq 1$ (adults 0.004 to 0.317 , children 0.016 to 1.77 ), indicating the calculated HM presented significant hazard through dermal absorption specially to children. The calculated $\mathrm{HQ}_{\text {ingesiton}}, \mathrm{HQ}_{\text {dermal }}$, and $\mathrm{HI}$ values for children were observed to be higher than those for adults. The order of $\mathrm{HI}$ in drinking water was $\mathrm{Ni}>\mathrm{Pb}>\mathrm{Co}>\mathrm{Cu}>\mathrm{Zn}$ in children and $\mathrm{Co}$ $>\mathrm{Ni}>\mathrm{Pb}>\mathrm{Cu}>\mathrm{Zn}$ in adults. The results of the present study are in good agreement with the study conducted by Mahfooz et al. (2019) who stated that the HM posed hazard to the inhabitants causing different diseases such as stomach and lung cancer, hypertension, anemia, physiological disabilities, and cardiac arrest. The findings of our study were found

Table 3 Reference dose (RfD), hazard quotient (HQ), and hazard index (HI) for each heavy metal

\begin{tabular}{|c|c|c|c|c|c|c|c|c|}
\hline \multirow[t]{2}{*}{$\mathrm{HM}$} & \multirow[t]{2}{*}{$\mathrm{RfD}_{\text {ingestion }}$} & \multirow[t]{2}{*}{$\mathrm{RfD}_{\text {dermal }}$} & \multicolumn{2}{|c|}{$\mathrm{HQ}_{\text {ingestion }}$} & \multicolumn{2}{|l|}{$\mathrm{HQ}_{\text {dermal }}$} & \multicolumn{2}{|c|}{$\mathrm{HI}=\mathrm{HQs}$} \\
\hline & & & Adult & Child & Adult & child & Adult & Child \\
\hline $\mathrm{Zn}$ & 300 & 60 & 0.00259 & 0.00269 & 0.00405 & 0.0168 & 0.00664 & 0.0168 \\
\hline Co & 5 & 0.06 & 0.10995 & 0.11435 & 0.26655 & 4.75992 & 0.3765 & 1.75992 \\
\hline $\mathrm{Cu}$ & 40 & 12 & 0.02406 & 0.02503 & 0.04187 & 0.26043 & 0.06593 & 0.26043 \\
\hline $\mathrm{Ni}$ & 20 & 5.4 & 0.04106 & 0.0427 & 0.31754 & 1.77752 & 0.3586 & 1.77752 \\
\hline $\mathrm{Pb}$ & 1.4 & 0.42 & 0.196 & 0.20384 & 0.0341 & 0.70705 & 0.2301 & 0.70705 \\
\hline
\end{tabular}


higher than those reported by Meng et al. (2016) who assessed Dan River drainage (China) water samples for human health risk through HQ by ingestion and HQ by skin. The calculated result in our study through $\mathrm{HQ}_{\text {dermal }}$ was found above unity for $\mathrm{Ni}$ and $\mathrm{Co}$ as shown in Table 3.

\section{Statistical analysis}

The correlation among HM and physicochemical parameters can provide useful information on the sources and the emission pathways. Correlation matrix was calculated by the Pearson's correlation coefficients for the elements and the results are shown in Table 4 . The correlation constant $(r)$ value identifies how significantly and conveniently the water samples are arranged in a simple and straight line. A number of significant positive correlations existed among the selected elements. The element/parameter pairs $\mathrm{pH}-\mathrm{Mg}, \mathrm{EC}-\mathrm{TDS}$, and $\mathrm{Na}-\mathrm{Mg}$ had a significant positive correlation at $<0.01$ significance level, and the element pairs $\mathrm{Zn}-\mathrm{Ni}$ and $\mathrm{K}-\mathrm{Mg}$ had a significantly positive correlation at $<0.05$ significance level showing that the elements were discharged from the same sources. The main sources of these metals in the water may be from the application of inorganic and nitrogenous and phosphate fertilizers and from animal manures. The combustion of coal and other fuels such as wood, rubber, tires, and other plastic wastes in brick kilns is one of the responsible sources for the emission of HM into the surrounding ambient environment (Khalid 2019).

The PCA was applied to identify the origins of HM in water samples. PCA aims to reduce the dimensionality of a multivariate dataset into fewer components which describes and explains most of the information contained in the data. The KMO value for water was 0.364 , and the significance of
Table 5 Principal component analysis via dimension reduction method after varimax rotation

\begin{tabular}{llllll}
\hline $\mathrm{HM}$ & $\mathrm{F} 1$ & $\mathrm{~F} 2$ & $\mathrm{~F} 3$ & $\mathrm{~F} 4$ & $\mathrm{~F} 5$ \\
\hline $\mathrm{pH}$ & -0.45 & 0.18 & -0.67 & -0.02 & 0.39 \\
$\mathrm{EC}$ & 0.37 & -0.54 & -0.02 & 0.53 & 0.02 \\
$\mathrm{TDS}$ & 0.02 & -0.70 & 0.07 & 0.43 & 0.28 \\
$\mathrm{Na}$ & 0.73 & 0.10 & -0.23 & 0.26 & 0.18 \\
$\mathrm{~K}$ & 0.60 & -0.22 & 0.30 & -0.37 & 0.33 \\
$\mathrm{Ca}$ & 0.39 & 0.12 & -0.64 & -0.10 & -0.38 \\
$\mathrm{Mg}$ & 0.76 & 0.04 & 0.14 & -0.26 & -0.14 \\
$\mathrm{Zn}$ & 0.45 & 0.46 & 0.08 & 0.42 & -0.40 \\
$\mathrm{Co}$ & 0.32 & 0.32 & 0.36 & -0.29 & 0.21 \\
$\mathrm{Cu}$ & 0.01 & 0.58 & 0.09 & 0.05 & 0.46 \\
$\mathrm{Ni}$ & 0.13 & 0.57 & 0.08 & 0.60 & 0.23 \\
$\mathrm{~Pb}$ & -0.58 & 0.15 & 0.56 & 0.22 & -0.26 \\
Eigenvalue & 2.09 & 1.93 & 1.77 & 1.77 & 1.09 \\
Variability \% & 17.4 & 16.0 & 14.7 & 14.7 & 9.15 \\
Cumulative \% & 17.4 & 33.4 & 48.2 & 63.0 & 72.2 \\
\hline
\end{tabular}

Values of dominant parameters in each factor are represented in italic

Bartlett's sphericity test was 0.01 , indicating that the PCA was effective for the studies (Varol 2011). PCA of the whole dataset contributed a maximum of five (5) components responsible for $72.02 \%$ of the total variance having eigenvalue $(\lambda)>1.0$ (Table 5). The first component (varifactor) of the PCA was responsible for $17.41 \%$ of the total variance correlated (loading $>0.60$ ) with $\mathrm{Na}, \mathrm{Mg}$, and $\mathrm{K}$. VF1 shows the strength of the LM suggesting that sodium, magnesium, and potassium have a dominant role in factor loading contribution. The second varifactor (VF2) explained $16.07 \%$ of the total variance mainly participated by $\mathrm{Cu}$ and $\mathrm{Ni}$ which strongly

Table 4 Pearson correlation matrix of heavy metals in the study area

\begin{tabular}{lllllllllllll}
\hline $\mathrm{HM}$ & $\mathrm{pH}$ & $\mathrm{EC}$ & $\mathrm{TDS}$ & $\mathrm{Na}$ & $\mathrm{K}$ & $\mathrm{Ca}$ & $\mathrm{Mg}$ & $\mathrm{Zn}$ & $\mathrm{Co}$ & $\mathrm{Cu}$ & $\mathrm{Ni}$ & $\mathrm{Pb}$ \\
\hline $\mathrm{pH}$ & 1.00 & -0.24 & -0.06 & -0.13 & -0.34 & 0.12 & $-0.41^{*}$ & -0.29 & -0.16 & 0.105 & 0.10 & -0.13 \\
$\mathrm{EC}$ & -0.24 & 1.00 & $0.50^{* *}$ & 0.31 & 0.14 & 0.10 & 0.031 & 0.10 & -0.06 & -0.18 & -0.02 & -0.16 \\
$\mathrm{TDS}$ & -0.06 & $\mathbf{0 . 5 0 *}$ & 1.00 & -0.03 & 0.11 & -0.20 & -0.05 & -0.16 & -0.20 & -0.25 & -0.02 & -0.08 \\
$\mathrm{Na}$ & -0.13 & 0.31 & -0.03 & 1.00 & 0.24 & 0.21 & $0.49^{* *}$ & 0.27 & -0.00 & 0.09 & 0.31 & $-0.4^{* *}$ \\
$\mathrm{~K}$ & -0.34 & 0.14 & 0.11 & 0.24 & 1.00 & 0.06 & $0.45^{*}$ & -0.03 & 0.29 & 0.04 & -0.12 & -0.32 \\
$\mathrm{Ca}$ & 0.12 & 0.10 & -0.20 & 0.21 & 0.06 & 1.00 & 0.22 & 0.25 & 0.06 & -0.10 & -0.01 & $-0.41^{*}$ \\
$\mathrm{Mg}$ & $0.41^{*}$ & 0.03 & -0.05 & $\mathbf{0 . 4 9}$ & $\mathbf{0 . 4 5}$ & 0.22 & 1.00 & 0.23 & 0.21 & -0.04 & -0.03 & -0.29 \\
$\mathrm{Zn}$ & -0.29 & 0.10 & -0.16 & 0.27 & -0.03 & 0.250 & 0.23 & 1.00 & 0.11 & 0.16 & $0.40^{* *}$ & -0.05 \\
$\mathrm{Co}$ & -0.16 & -0.06 & -0.20 & -0.03 & 0.29 & 0.06 & 0.22 & 0.11 & 1.00 & 0.09 & 0.21 & -0.11 \\
$\mathrm{Cu}$ & 0.10 & -0.18 & -0.25 & 0.09 & 0.04 & -0.10 & -0.04 & 0.16 & 0.09 & 1.00 & 0.25 & 0.03 \\
$\mathrm{Ni}$ & 0.10 & -0.02 & -0.02 & 0.31 & -0.12 & -0.01 & -0.03 & $\mathbf{0 . 4 0}$ & 0.21 & 0.25 & 1.00 & 0.15 \\
$\mathrm{~Pb}$ & -0.13 & -0.16 & -0.08 & $\mathbf{0 . 4 7}$ & -0.32 & $0.41^{*}$ & -0.29 & -0.05 & -0.12 & 0.03 & 0.15 & 1.00 \\
\hline
\end{tabular}

*** Correlation is significant at the 0.01 level (2-tailed). ${ }^{*}$ Correlation is significant at the 0.05 level (2-tailed)

Values of dominant parameter in each factor are dominated in bold. Italic data are given for the same parameter correlation with each othe 

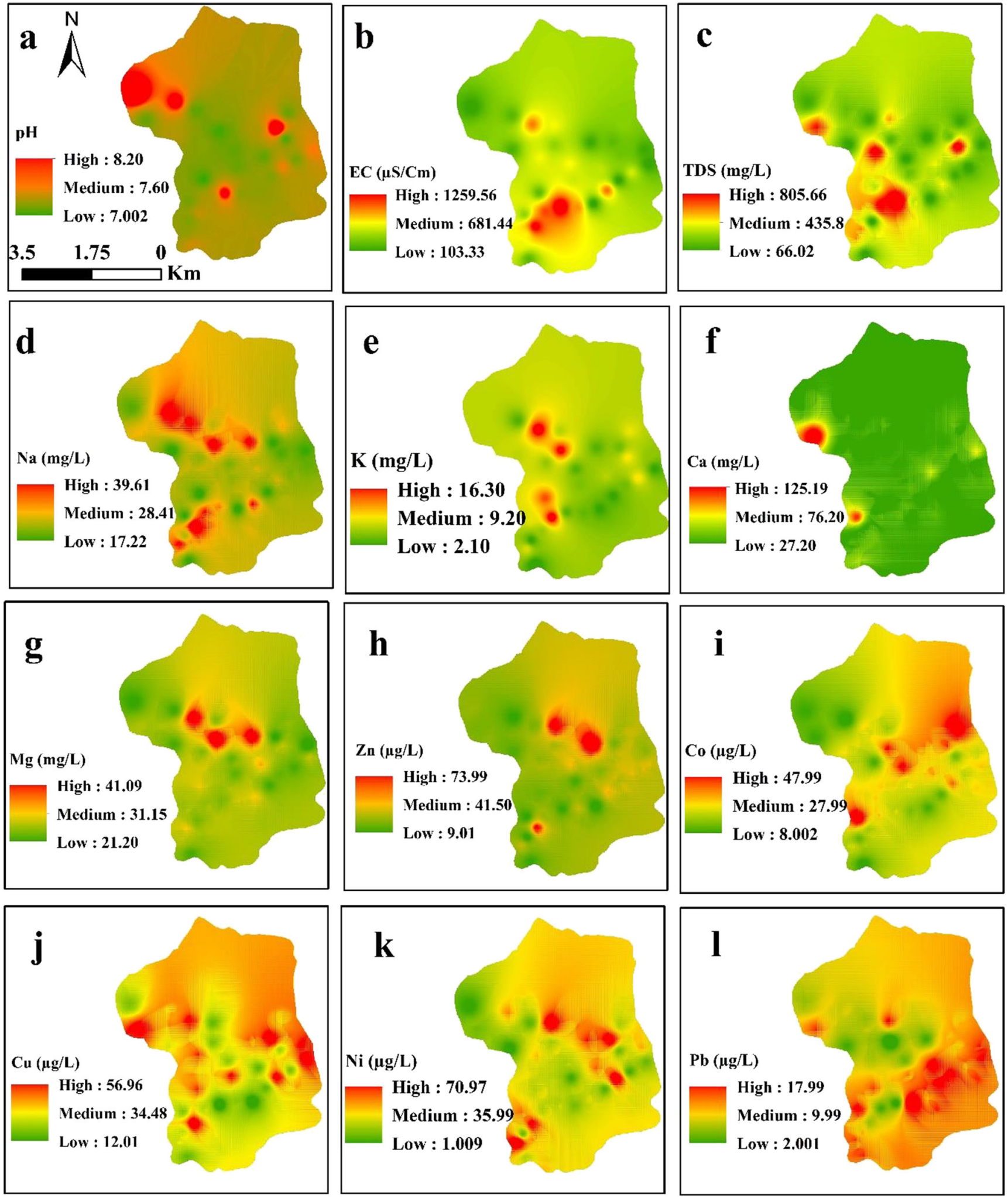

Fig. 6 Spatial distribution maps of physicochemical parameters and heavy metals in water samples

correlated with high loadings $(>0.50)$. It was noteworthy that the high contents of these metals could be related to anthropogenic activities such as industrial processes and agrofertilizer application and commercial and electroplating industries (Gao et al. 2019). The 3rd varifactor (VF3) identifies the influence of $\mathrm{Pb}$ and their loading value was observed 
to be greater than 0.56 indicating a mixed source of natural and anthropogenic sources that influence the water quality in the study area. The 4th and 5th varifactors (VF4 and VF5) show significant loading for $\mathrm{Ni}(>0.64)$ and $\mathrm{Cu}(>0.46)$, respectively. These factors can promote the dissolution of $\mathrm{Cu}$ and Ni minerals in the water aquifers in the study area.

\section{Spatial distribution mapping}

Spatial distribution pattern maps of the physicochemical parameters and HM for water samples were drawn using interpolation and kriging techniques which are easily and understandable geostatistical approaches for spatial distribution pattern maps in water (Rashid et al. 2019a). Thus, pH, EC, TDS, $\mathrm{Na}, \mathrm{K}, \mathrm{Ca}, \mathrm{Mg}, \mathrm{Zn}, \mathrm{Co}, \mathrm{Cu}, \mathrm{Ni}$, and $\mathrm{Zn}$ were mapped using spatial interpolation kriging techniques. Different classes were assigned representing low, medium, and high concentrations in the study area. The spatial variation of the physicochemical parameters and HM in water samples of the study area is shown in Fig. 6. pH is spatially distributed in the water samples of the study area as shown in Fig. 4a. pH was found higher in $30 \%$ of the water samples than the recommended guideline values. Although $\mathrm{pH}$ affects palatability and has no direct health impacts, it is an important operational water quality parameter. It can affect the corrosivity power of water. At $\mathrm{pH}$ above 8 , the disinfecting tendency of chlorine decreases and its corrosiveness increases below pH 7 (Ahmed et al. 2015).

Similarly, EC and TDS are spatially distributed and three different classes have been obtained on the basis of its concentration as shown in Fig. 6 b and c, respectively. The three classes are green (low concentration), yellow (medium concentration), and red (highest concentration). The measurement of EC is related to the concentration of ionized substances in water and may be related to the excessive hardness and mineral contamination. In case of TDS, about $75 \%$ was found within the desirable limit of $500 \mathrm{mg} / \mathrm{L}$, while $25 \%$ of the water samples were found above the desirable limit of $1000 \mathrm{mg} / \mathrm{L}$. Water containing TDS more than $500 \mathrm{mg} / \mathrm{L}$ causes gastrointestinal irritation (Jehan et al. 2019b). The concentration ranges for $\mathrm{LM}$ like $\mathrm{Na}$ and $\mathrm{K}$ were 17.22 to $39.61 \mathrm{mg} / \mathrm{L}$ and 2.10 to $16.30 \mathrm{mg} / \mathrm{L}$, respectively, in the study area (Fig. 6d, e). The concentration of $\mathrm{Na}$ was quite low in the study area, while in $34 \%$ of the water samples, $\mathrm{K}$ content was found higher than the maximum allowable limit of $12 \mathrm{mg} / \mathrm{L}$ (WHO 2011). The main sources of $\mathrm{K}$ in water include weathering of potash silicate minerals, the use of potash fertilizers and rain water, and the use of surface water for irrigation. Similarly, three categories were classified for the concentration of $\mathrm{Ca}$ and $\mathrm{Mg}$ which ranged from 27.20 to $125 \mathrm{mg} / \mathrm{L}$ and 21.20 to $41.09 \mathrm{mg} / \mathrm{L}$, respectively (Fig. $6 \mathrm{f}$, g). The maximum desirable limit for $\mathrm{Ca}$ and $\mathrm{Mg}$ is 75 and $50 \mathrm{mg} / \mathrm{L}$, respectively. In water samples of the study area, $\mathrm{Ca}$ content slightly exceeds the $\mathrm{Mg}$ concentration in accordance with their relative abundance in the host rocks. The spatial variation of $\mathrm{Ca}$ (Fig. $6 \mathrm{f}$ ) shows that the area is exceeding the desirable limit $(<75 \mathrm{mg} / \mathrm{L})$ and surpassed the permissible limits $(75-200 \mathrm{mg} / \mathrm{L}$ ) which correspond to $90 \%$ and $10 \%$, respectively. The spatial variation of $\mathrm{Mg}$ (Fig. $6 \mathrm{~g}$ ) shows that in the entire study area, the water samples fall in the desirable limit $(50 \mathrm{mg} / \mathrm{L})$ during the study.

Zinc is spatially distributed in the water samples of the study area (Fig. 6h). The 9.01 value represents the minimum concentration and 73.99 indicates highest concentration falling in the desirable limit of 3000 for zinc. The entire water samples in the study area were within the maximum desirable limit of $3000 \mu \mathrm{g} / \mathrm{L}$ set by the WHO (2011). Similarly, there are two classes for $\mathrm{Co}$ - lowest to highest - ranging from 8.00 to $48.00 \mu \mathrm{g} / \mathrm{L}$ in the study area (Fig. 6i). The distribution map of $\mathrm{Cu}$ at different classes ( 12.01 to $57.00 \mu \mathrm{g} / \mathrm{L}$ ) is shown in Fig. 6j. The desirable limit for $\mathrm{Cu}$ is $50 \mu \mathrm{g} / \mathrm{L}$. In water samples of the study area, $\mathrm{Cu}$ exceeds in $34 \%$ of the total analyzed samples. $\mathrm{Cu}$ is considered an essential micronutrient, but at high concentration, it can cause liver and kidney failure, nausea, vomiting, and gastrointestinal problems. The distribution pattern map of $\mathrm{Ni}$ is shown in Fig. 6k. Two classes differentiate the highest to lowest concentration of $\mathrm{Ni}$ ranging from 1.00 to $71.97 \mu \mathrm{g} / \mathrm{L}$ in the study area. The maximum desirable limit set by the WHO (2011) for Ni is $20 \mu \mathrm{g} / \mathrm{L} ; 60 \%$ of the samples were above the recommended desirable limit. Ni content can induce nasal and lung problems when ingested at a higher dose. There are two classes (lowest and highest) for $\mathrm{Pb}$ concentration that show the $\mathrm{Pb}$ level in the water samples of the study area. The lowest $(2.00 \mu \mathrm{g} / \mathrm{L})$ and highest $(17.98 \mu \mathrm{g} / \mathrm{L})$ concentrations of $\mathrm{Pb}$ were recorded in the study area (Fig. 61). The maximum desirable limit of $10 \mu \mathrm{g} / \mathrm{L}$ was set by the WHO (2011); $56 \%$ of the samples were observed to be higher than the desirable limit. The distribution pattern of HM showed that water in the study area is contaminated with $\mathrm{Ni}, \mathrm{Cu}$, and $\mathrm{Pb}$; therefore, it is recommended that local residents should use safe groundwater sources for drinking/domestic and bathing needs.

\section{Conclusion}

The present research work thoroughly and briefly describes the water quality and human health risk along the Swat River, Northern Pakistan. Results indicated that large variations of HM in water sample were found in the study area. Among the investigated $\mathrm{HM}$ viz. $\mathrm{Ni}, \mathrm{Cu}$, and $\mathrm{Pb}$ originated from anthropogenic inputs mainly from industrial and agricultural practices and weathering of bed rocks. The poor water quality in this area was mainly related to high alkalinity and salinity hazard. The WQI model also showed that water quality of the study area was found to be unsuitable for drinking and domestic purposes. Similarly, water quality for irrigation in terms of the quality indicator such as SAR was not suitable for irrigation. The noncarcinogenic risk 
assessment indicated that there was NCR to humans through ingestion and dermal absorption (i.e., $\mathrm{HQ}_{\text {ingestion, }} \mathrm{HQ}_{\text {dermal }}$, and $\mathrm{HI} \geq 1$ ). Children were more sensitive than adults to the noncarcinogenic hazards, based on the HQ and HI value for children and adults. The results of multivariate statistical analysis showed that the water of the study area was greatly influenced by anthropogenic activities such as agricultural and industrial processes and commercial wastewater emission from the surrounding populated city of Batkhela. Therefore, to ensure public health and safety, it is necessary to make regular monitoring assessment of exposure to HM in the district of Batkhela, Pakistan.

Acknowledgments The authors acknowledge the National Centre of Excellence in Geology University of Peshawar for technical support and the Department of Environmental Sciences, University of Haripur, Pakistan. We are greatly grateful for the in-depth discussion by the anonymous reviewers that have improved the quality of the manuscript.

\section{Compliance with ethical standards}

Conflict of interest The authors declare that they have no conflict of interest.

Open Access This article is licensed under a Creative Commons Attribution 4.0 International License, which permits use, sharing, adaptation, distribution and reproduction in any medium or format, as long as you give appropriate credit to the original author(s) and the source, provide a link to the Creative Commons licence, and indicate if changes were made. The images or other third party material in this article are included in the article's Creative Commons licence, unless indicated otherwise in a credit line to the material. If material is not included in the article's Creative Commons licence and your intended use is not permitted by statutory regulation or exceeds the permitted use, you will need to obtain permission directly from the copyright holder. To view a copy of this licence, visit http://creativecommons.org/licenses/by/4.0/.

\section{References}

Abbasnia A, Radfard M, Mahvi AH, Nabizadeh R, Yousefi M, Soleimani H, Alimohammadi M (2018) Groundwater quality assessment for irrigation purposes based on irrigation water quality index and its zoning with GIS in the villages of Chabahar, Sistan and Baluchistan, Iran. Data in Brief 19:623-631

Ahmed PA, Mehtab M, Sherwani SK (2015) Assessment of drinking water quality and its potential health impacts in academic institutions of Abbottabad (Pakistan). Desalin Water Treat 54:1819-1828

Ali L, Rashid A, Khattak SA, Zeb M, Jehan S (2019) Geochemical control of potential toxic elements (PTEs), associated risk exposure and source apportionment of agricultural soil in southern Chitral, Pakistan. Microchem J 147:516-523

Arain MA, Haque Z, Badar N, Mughal N (2009) Drinking water contamination by chromium and lead in industrial lands of Karachi. JPMA The Journal of the Pakistan Medical Association 59:270

Ashraf M, Tariq J, Jaffar M (1991) Contents of trace metals in fish, sediment and water from three freshwater reservoirs on the Indus River, Pakistan. Fish Res 12:355-364

Avci H, Dokuz UE, Avci AS (2018) Hydrochemistry and groundwater quality in a semiarid calcareous area: an evaluation of major ion chemistry using a stoichiometric approach. Environ Monit Assess 190:641

Barinova S, Ali N, Barkatullah SF (2013): Ecological adaptation to altitude of algal communities in the Swat Valley (Hindu Cush Mountains, Pakistan). Expert Opin Environ Biol 2(2)

Calazans GM, Pinto CC, da Costa EP, Perini AF, Oliveira SC (2018) Using multivariate techniques as a strategy to guide optimization projects for the surface water quality network monitoring in the Velhas river basin, Brazil. Environ Monit Assess 190:726

Chadha D (1999) A proposed new diagram for geochemical classification of natural waters and interpretation of chemical data. Hydrogeol $\mathrm{J} 7$ : 431-439

Chuma C, Orimoogunje OO, Hlatywayo DJ, Akinyede JO (2013): Application of remote sensing and geographical information systems in determining the groundwater potential in the crystalline basement of Bulawayo metropolitan area, Zimbabwe

Ekere NR, Agbazue VE, Ngang BU, Ihedioha JN (2019) Hydrochemistry and water quality index of groundwater resources in Enugu north district, Enugu, Nigeria. Environ Monit Assess 191:150

El Hamouri B, Handouf A, Mekrane M, Touzani M, Khana A, Khallayoune K, Benchokrount T (1996) Use of wastewater for crop production under arid and saline conditions: yield and hygienic quality of the crop and soil contaminations. Water Sci Technol 33: 327-334

Gao B, Gao L, Gao J, Xu D, Wang Q, Sun K (2019) Simultaneous evaluations of occurrence and probabilistic human health risk associated with trace elements in typical drinking water sources from major river basins in China. Sci Total Environ 666:139-146

Gibbs RJ (1970) Mechanisms controlling world water chemistry. Science 170:1088-1090

Haq M (2005) Surface and ground water contamination in NWFP and Sindh provinces with respect to trace elements. International Journal of Agricultural Biology 7:214-217

Horton RK (1965) An index number system for rating water quality. Journal of Water Pollution Control Federation 37:300-306

Hou W, Sun S, Wang M, Li X, Zhang N, Xin X, Sun L, Li W, Jia R (2016) Assessing water quality of five typical reservoirs in lower reaches of Yellow River, China: using a water quality index method. Ecol Indic 61:309-316

Ilyas A, Sarwar T (2003): Study of trace elements in drinking water in the vicinity of Palosi drain, Peshawar. Pakistan Journal of Biological Sciences 6, 86-91

Jehan S, Khattak SA, Muhammad S, Ahmad R, Farooq M, Khan S, Khan A, Ali L (2018) Ecological and health risk assessment of heavy metals in the Hattar industrial estate. Pakistan Toxin Reviews:1-10

Jehan S, Khan S, Khattak SA, Muhammad S, Rashid A, Muhammad N (2019a) Hydrochemical properties of drinking water and their sources apportionment of pollution in Bajaur Agency, Pakistan. Measurement 139:249-257

Jehan S, Khattak SA, Muhammad S, Ali L, Rashid A, Hussain ML (2019b) Human health risks by potentially toxic metals in drinking water along the Hattar industrial estate. Pakistan Environmental Science and Pollution Research:1-14

Kelly WP (1957) Adsorbed sodium cation exchanges capacity and percentage sodium sorption in alkali soils. Science 84:473-477

Khalid S (2019) An assessment of groundwater quality for irrigation and drinking purposes around brick kilns in three districts of Balochistan province, Pakistan, through water quality index and multivariate statistical approaches. J Geochem Explor 197:14-26

Khan K, Lu Y, Saeed MA, Bilal H, Sher H, Khan H, Ali J, Wang P, Uwizeyimana H, Baninla Y, Li Q, Liu Z, Nawab J, Zhou Y, Su C, Liang R (2018) Prevalent fecal contamination in drinking water resources and potential health risks in Swat, Pakistan. J Environ Sci $72: 1-12$ 
Ladwani KD, Ladwani KD, Manik VS, Ramteke D (2012) Impact of domestic wastewater irrigation on soil properties and crop yield. Int J Sci Res Publ 2:1-7

Lazarova V, Bahri A (2004) Water reuse for irrigation: agriculture, landscapes, and turf grass. CRC

Li P, Wu J, Qian H, Zhang Y, Yang N, Jing L, Yu P (2016) Hydrogeochemical characterization of groundwater in and around a wastewater irrigated forest in the southeastern edge of the Tengger Desert, northwest China. Exposure and Health 8:331-348

Liu M, Xu Y, Nawab J, Rahman Z, Khan S, Idress M, Ud Din Z, Ali A, Ahmad R, Khan SA, Khan A, Khan MQ, Tang Y-T, Li G (2020) Contamination features, geo-accumulation, enrichments and human health risks of toxic heavy metal (loids) from fish consumption collected along Swat river, Pakistan. Environmental Technology \& Innovation 17:100554

Mahfooz Y, Yasar A, Sohail MT, Tabinda AB, Rasheed R, Irshad S, Yousaf B (2019): Investigating the drinking and surface water quality and associated health risks in a semi-arid multi-industrial metropolis (Faisalabad), Pakistan. Environmental Science and Pollution Research, 1-13

Maillard P, Santos NAP (2008) A spatial-statistical approach for modelling the effect of non-point source pollution on different water quality parameters in the Velhas river watershed-Brazil. J Environ Manag 86:158-170

Meng Q, Zhang J, Zhang Z, Wu T (2016) Geochemistry of dissolved trace elements and heavy metals in the Dan River drainage (China): distribution, sources, and water quality assessment. Environ Sci Pollut Res 23:8091-8103

Mohebbi MR, Saeedi R, Montazeri A, Vaghefi KA, Labbafi S, Oktaie S, Abtahi M, Mohagheghian A (2013) Assessment of water quality in groundwater resources of Iran using a modified drinking water quality index (DWQI). Ecol Indic 30:28-34

Mukate S, Wagh V, Panaskar D, Jacobs JA, Sawant A (2019) Development of new integrated water quality index (IWQI) model to evaluate the drinking suitability of water. Ecol Indic 101:348-354

Nafees M, Jan MR, Khan H, Ali A (2008) Status of soil texture and required associated soil conservation measure of river swat catchments area, NWFP, Pakistan. Sarhad Journal of Agriculture 24:251259

Nasir MJ, Khan S, Zahid H, Khan A (2018) Delineation of groundwater potential zones using GIS and multi influence factor (MIF) techniques: a study of district Swat, Khyber Pakhtunkhwa, Pakistan. Environ Earth Sci 77:367

Omonona OV, Amah JO, Olorunju SB, Waziri SH, Ekwe AC, Olofinlade SW (2019) Hydrochemical characteristics and quality assessment of groundwater from fractured Albian carbonaceous shale aquifers around Enyigba-Ameri, southeastern Nigeria. Environ Monit Assess 191:125

Raju N, Shukla UK, Ram P (2011) Hydrogeochemistry for the assessment of groundwater quality in Varanasi: a fast-urbanizing center in Uttar Pradesh, India. Environ Monit Assess 173:279-300

Rashid A, Guan D-X, Farooqi A, Khan S, Zahir S, Jehan S, Khattak SA, Khan MS, Khan R (2018) Fluoride prevalence in groundwater around a fluorite mining area in the flood plain of the River Swat, Pakistan. Sci Total Environ 635:203-215

Rashid A, Khan S, Ayub M, Sardar T, Jehan S, Zahir S, Khan MS, Muhammad J, Khan R, Ali A (2019a) Mapping human health risk from exposure to potential toxic metal contamination in groundwater of Lower Dir, Pakistan: application of multivariate and geographical information system. Chemosphere

Rashid A, Khattak SA, Ali L, Zaib M, Jehan S, Ayub M, Ullah S (2019b) Geochemical profile and source identification of surface and groundwater pollution of district Chitral, Northern Pakistan. Microchem J 145:1058-1065

Rehman W, Zeb A, Noor N, Nawaz M (2008) Heavy metal pollution assessment in various industries of Pakistan. Environ Geol 55:353358

Rehman U, Khan S, Muhammad S (2018) Associations of potentially toxic elements (PTEs) in drinking water and human biomarkers: a case study from five districts of Pakistan. Environ Sci Pollut Res 25: 27912-27923

Samantara M, Padhi R, Sowmya M, Kumaran P, Satpathy K (2017) Heavy metal contamination, major ion chemistry and appraisal of the groundwater status in coastal aquifer, Kalpakkam, Tamil Nadu, India. Groundw Sustain Dev 5:49-58

Sánchez ERS, Hoyos SEG, Esteller MV, Morales MM, Astudillo AO (2017) Hydrogeochemistry and water-rock interactions in the urban area of Puebla Valley aquifer (Mexico). J Geochem Explor 181: 219-235

Searle MP, Khan MA (1996): Geological and tectonic map of Northern Pakistan and adjacent areas of Northern Ladakh and Western Tibet (coloured, 1:650,000). Sponsored Publication of British Petroleum, Shell and AMOCO, Chicago

Selvakumar S, Chandrasekar N, Kumar G (2017) Hydrogeochemical characteristics and groundwater contamination in the rapid urban development areas of Coimbatore, India. Water Resources and Industry 17:26-33

Solangi GS, Siyal AA, Babar MM, Siyal P (2019): Groundwater quality evaluation using the water quality index (WQI), the synthetic pollution index (SPI), and geospatial tools: a case study of Sujawal district, Pakistan. Human and Ecological Risk Assessment: An International Journal, 1-21

Tripathi M, Singal SK (2019) Use of principal component analysis for parameter selection for development of a novel water quality index: a case study of river Ganga India. Ecol Indic 96:430-436

USEPA 2011: Risk assessment guidance for superfund. Volume I: human health evaluation manual (part E, supplemental guidance for dermal risk assessment), $\mathrm{EPA} / 540 / \mathrm{R} / 99$

Varol M (2011) Assessment of heavy metal contamination in sediments of the Tigris River (Turkey) using pollution indices and multivariate statistical techniques. J Hazard Mater 195:355-364

Wang L, Wang Y, Xu C, An Z, Wang S (2011) Analysis and evaluation of the source of heavy metals in water of the river Changjiang. Environ Monit Assess 173:301-313

Wang Y, Wang R, Fan L, Chen T, Bai Y, Yu Q, Liu Y (2017) Assessment of multiple exposure to chemical elements and health risks among residents near Huodehong lead-zinc mining area in Yunnan, southwest China. Chemosphere 174:613-627

WHO (2011): Guidelines for drinking-water quality. WHO Chronicle 38, 104-108

Wu Z, Wang X, Chen Y, Cai Y, Deng J (2018) Assessing river water quality using water quality index in Lake Taihu Basin, China. Sci Total Environ 612:914-922

Xiao J, Wang L, Deng L, Jin Z (2019) Characteristics, sources, water quality and health risk assessment of trace elements in river water and well water in the Chinese Loess Plateau. Sci Total Environ 650: 2004-2012

Zeng X, Liu Y, You S, Zeng G, Tan X, Hu X, Hu X, Huang L, Li F (2015) Spatial distribution, health risk assessment and statistical source identification of the trace elements in surface water from the Xiangjiang River, China. Environ Sci Pollut Res 22:9400-9412

Publisher's note Springer Nature remains neutral with regard to jurisdictional claims in published maps and institutional affiliations. 